\title{
RESEARCH AND EVALUATION
}

\section{Implementing Joined-Up Government: Lessons from the Australian Social Inclusion Agenda}

\author{
Gemma Carey \\ National Centre for Epidemiology and Population Health, ANU
}

\author{
Pauline McLoughlin \\ Centre for Applied Social Research, RMIT University
}

\author{
Brad Crammond \\ Public Health and Preventive Medicine, Monash University
}

\begin{abstract}
'Joined-up government' (JUG) approaches have emerged in many industrialized countries as a means to tackle persistent 'wicked' public and social policy problems (Pollit 2003). Despite this, limited evidence exists concerning their implementation or effectiveness. ' $U U G$ ' was popularized by the Blair Government (UK) with its focus on addressing social exclusion. Following in these footsteps, in 2007 the Australian Government launched the Social Inclusion Agenda: a joined-up approach to improving the wellbeing of all Australians and addressing disadvantage. This paper focuses on findings from a study that examined the SIA as a natural experiment in JUG. Drawing on the implementation experiences of federal policy makers, our findings lend weight to emerging research into JUG that suggests that compatibility and consistency between goals, instruments, and processes is critical to success. We argue that closer attention needs to be given to developing 'supportive architecture' around joined-up initiatives to facilitate implementation.
\end{abstract}

Key words: government integration, joined-up government, policy implementation, social inclusion, whole-of-government

\section{Introduction and Background}

Although coordination has long been a concern of government, since the late 1990s there has been a push amongst industrialized countries towards joined-up government (JUG) as a means to address complex wicked policy problems and overcome 'siloed' departmental approaches (6 2004; Christensen and Laegreid 2007, 2006; Rittel and Webber 1973). For example, joined-up approaches have been utilized in attempts to address domestic violence
(Office of Women's Policy 2002), drugs and crime (Homel et al. 2004), and homelessness (Commonwealth Department of Family and Community Services 2005). The goals of JUG are: to improve the efficacy of policies by removing tensions and contradictions, to create more efficient use of resources, improve cooperation, and provide citizens with more integrated services (Pollitt 2003). However, knowledge of how to create JUG is still limited (Keast 2011). 'JUG' is an 'umbrella' term. How it is 'done' depends on the characteristics 
of the government of the day, its political imperatives, and the nature of the problem(s) being addressed (Davies 2009; Richards 2001). There is growing interest in understanding how whole-of-government approaches are created and whether they are appropriate or effective in combating the problems they set out to address (Christensen and Laegreid 2007; Pollitt 2003; Ross et al. 2011).

In 2007, the Australian Federal Government launched a 'joined-up' approach to address the 'wicked' problem of social exclusion (Australian Public Service Commission 2007). Wicked policy problems tend to have no definitive solution; they cross traditional boundaries and institutions, and have many interdependencies and causes (Rittel and Webber 1973). This means they often have internally conflicting goals or objectives and are socially complex. Wicked problems are rarely solved in their entirety, with solutions forming the basis of new, complex challenges. Social exclusion, then, is wicked in the sense that it is multidimensional, complex, and contested (Silver 1994). Different stakeholders will define problems of exclusion in different ways, and will put forth solutions accordingly, which may conflict. Wicked problems that have received substantial policy attention include unemployment, poverty, and education challenges - all of which were identified as areas of concern under the Social Inclusion Agenda (SIA).

Through the SIA the former Labor Government sought to strengthen the Australian welfare state, reducing inequality and disadvantage while building social, economic, and civic participation to improve the wellbeing of all Australians (Gillard and Wong 2007). This study explored the implementation experiences of senior federal policy makers. Findings lend weight to emerging research that suggests that compatibility and consistency between goals, instruments, and processes is critical to the success of JUG (Keast 2011). We argue that closer attention needs to be given to developing 'supportive architecture' (O'Flynn 2013; O’Flynn et al. 2011) around joined-up initiatives like the SIA to facilitate implementation.

\section{Methods}

The aim of the study is to explore the implementation experiences of key social policy actors involved in the implementation of the Australian SIA, specifically with relation to two instruments used to create JUG under the initiative.

Social policy implementation research is a contested field. Hill and Hupe (2009) have gone so far as to suggest that many policies developed by governments are not worth studying because the intentions of policy makers are unclear and, as a result, may simply be too difficult to study. Despite this, a degree of consensus has emerged around the importance of organizations and staff in the implementation process. Since the 1970 s, the 'implementation behaviour' of organizations has been of central interest to policy implementation scholars (Friedman 2006; Kettl 2000; Lipsky 1980; Pressman and Wildavsky 1984). Policies are understood to be 'substantially shaped by the organisations that operate between inputs and outputs' (Meyers and Dillon 1999: 233), making 'organisational analysis a major concern for policy' (Friedman 2006: 482).

Policies are shaped by the practices of staff embedded in implementing organizations, which have in turn been found to be based upon past experiences, existing knowledge, and organizational norms and values (Hill and Hupe 2009; Riccucci et al. 2004; Sandfort 1999). To investigate these, the research used an interpretivist approach, which enables us to view people as actors in a social world, rather than objects reacting in the natural world. An interpretivist lens attempts to make sense of phenomena through the meanings people bring to them (O'Reily 2005). Here, the researcher is able to 'discover the explanations, rationales, anecdotes, normative views, myths and mysteries' that exist, for example within implementing organizations (Smircich 1983: 162).

Three government departments were identified that were principally responsible for the design and/or implementation of the SIA. Snowball sampling was conducted in order to identify participants. Six semi-structured 
Table 1. Participants' department and the code that interview quotes will be attributed to throughout the paper

\begin{tabular}{lc}
\hline Department & Code \\
\hline Department 1 & $\mathrm{G} 01$ \\
Department 1 & $\mathrm{G} 02$ \\
Department 2 & $\mathrm{G} 03$ \\
Department 1 & $\mathrm{G} 04$ \\
Department 3 & $\mathrm{G} 05$ \\
Department 2 & $\mathrm{G} 06$ \\
\hline
\end{tabular}

interviews were conducted in total. Participants ranged from current and past deputy departmental secretaries and directors of units, to current and former branch managers and senior advisors (e.g. to the Prime Minister) (see Table 1 for list of participants and departmental affiliations). Although all participants were public servants, one had previously been a political appointment (i.e. a 'policy adviser'). Sampling continued until interviewees were unable to suggest other potential participants or began to nominate individuals already interviewed. Given the small number of individuals able to comment on the Agenda and the very senior nature of the participants (combined with the fact that interviewees began to nominate individuals already interviewed), one can infer that the 'population' of potential participants was largely exhausted, despite the small sample size. It is worth noting, however, that the different experiences of the SIA may have existed in parts of government not captured within this sample.

Themes covered in the interviews included: the vision and scope of the SIA, implementation of the SIA within government, effectiveness of new administrative structures.

Thematic analysis was conducted. Through a process akin to open coding (Strauss 1987), 'like' data were grouped together to form categories and subcategories. These categories were gradually developed into themes, by linking and drawing connections between initial categories and hypothesizing about consequences and likely explanations for the appearance of certain phenomena (Strauss 1987).

\section{Findings and Discussion}

JUG is a term that encapsulates a desire to achieve vertically and horizontally co-ordinated action and thinking. Public administration scholars have identified two levels of intervention for creating this coordination (Klijn and Koppenjan 1997, 2000). The first is at the institutional level. Institutional change is important because interaction depends upon 'institutional' factors, such as relationships, the interdependencies between different actors, and the rules that guide action (Klijn and Koppenjan 1997, 2000). Interventions at this level seek to change the institutional context, or 'culture', in order to create the preconditions for change. The second point of intervention is at the level of structure and process. Interventions at this level seek to alter the structure of the network, thereby influencing the nature and processes of interaction between actors.

Consistent with this, the study found that the implementation of the SIA was pursued on two levels. The first involved efforts to create cultural and institutional change through the adoption of a policy current, or policy narrative, of social inclusion. Emerging from the Blair Government's experimentation with Third Way ideas in the United Kingdom, policy currents are said to sit 'above' policies and act as a rallying call, directional pointer, and broad benchmark for change (Bills 2001; Miller 2012). The limited available literature on policy currents describes them as fluid, guiding policies, or principles that move across departmental boundaries (Bills 2001). They articulate a shared vision and set of values, which act to guide and inform policy making across government departments and are the responsibility of no single department, but carry implications for all departments. Policy currents are an attempt to create essential 'cultural-institutional' change by uniting stakeholders behind a common goal (Christensen and Laegreid 2007).

On the second level of implementation, the policy narrative was coupled with the introduction of new administrative structures, designed to create changes in processes. An advisory body - the Social Inclusion Board - was established to provide direction on issues relating to 
social inclusion from experts outside of government. This was followed by the creation of the Social Inclusion Unit - an interdepartmental working committee located in the Department of Prime Minister and Cabinet (PMC). Administrative structures such as interdepartmental taskforces and intergovernmental committees are common features of JUG approaches. Their aim is to create integration across 'siloed' departments, promoting agreement, collaboration, and the tackling of inconsistent policies (Pollitt 2003; Richards 2001). Although limited public information was made available on the unit and its functions, broadly it sought to develop a shared understanding of, and coordinate efforts to embed, social inclusion approaches across agencies and jurisdictions (Commonwealth of Australia 2009).

Below, we explore the implementation of each of these interventions and the lessons that emerge from the SIA regarding their effectiveness as 'tools' for implementing JUG.

\section{Policy Narratives as Tools for JUG}

Policy narratives, or currents, are seen as a way to create cultural and institutional change. Under the SIA, this was a focus on social inequality and addressing social disadvantage through increased economic and civic participation (or 'social inclusion'). Policy currents are equivalent to emerging concepts discussed in the organizational management literature. For organizational change, Bartel and Garud encourage the use of 'innovation narratives' (Bartel and Garud 2009). Like policy currents, innovation narratives promote the coordination of people and ideas across organizations, shaping practice through the power of language and the story about an innovation (such as a new approach to policy). These 'communicative' instruments are not intended to modify behaviour as such, but to bring about change in how actors perceive the problem and, through this, shift values (Klijn and Koppenjan 1997). This is based on the rationale that actors will be more open to process-related changes where there has been a prior shift in their values.

When asked whether policy narratives were valuable tools for change, participants stated that having the 'narrative' of social inclusion helped to articulate the government's values. In this sense, the policy current acted as a critical rallying point, creating opportunities for new policy windows:

By having the Agenda you go some way to ensuring that the reforms that are undertaken and what the government is doing aligns with those general principles - just because it's there it helps [G03].

... value was created by the government being clear that they wanted to pursue a Social Inclusion Agenda. And it gets into people's minds, and it provides a hook to have policy discussions that you might not otherwise have had. So it's kind of indirect. [G03]

Communicative tools, such as policy narratives, are seen as soft interventions, which articulate new policy problems but are not aimed at creating changes in process. Nonetheless, under the SIA policy makers attempted to operationalize the narrative and apply it to their practice, in terms of the design and conceptualization of policies and programs:

Whenever you have a narrative that's big like social inclusion... it can get torn down so quickly. So the Social Inclusion Agenda is ... at a high level, so you can go okay, there's your social inclusion narrative that means we want everyone to be able to participate in society and to be able to access things that other people can access. [But we] don't have enough money to do that... So it's easy to have your narrative, but at the level of policy [is where] you get all the arguments. [G04]

Although effective policy narratives are thought to be inspirational, in this instance the scale of change articulated by the narrative of social inclusion was prohibitive. The idea that all Australians should be given the opportunity to be socially, economically, and civically included was difficult for policy makers to translate into practice. In particular, the SIA was seen as having diffuse, or vague, domains of responsibility:

I think if you ask the Prime Minister or the Minister, she would say, 'everything we do, as a Labor Party, is committed to that broad national social 
inclusion'... So I mean I think it provides a strong motivator for many of the parliamentary MPs, but it's too big for any one department to say, 'well I'm going to tackle that big vision'. [G06]

I think the reason, the rationale now for [what we are] doing is to actually give the social inclusion a sharp focus, where it has been too diffuse in its intentions and therefore been into everything, but influencing nothing. And in a pragmatic sense that's pretty ineffective. [G05]

In the statement below, a policy maker explains how the launch of the SIA was met with considerable debate. Specifically, this focused on whether it was practicable to implement an Agenda aimed at the whole population or whether they needed a more targeted approach, which policy makers were more accustomed to implementing:

I think there was some confusion initially in government about how hard they were focusing on it, what the breadth of the definition was. And that firmed up over time as people started to talk about it and work through the practicalities of it. There was a lot of discussion about [the balance] in the bureaucracy... Just what are we looking for? How do we approach this? How do we implement this Agenda? Do we do a big broad picture and try and attack everything or do we target? And in the end my understanding is that they decided to target. [G02]

As this participant suggests, during implementation those within government began to gravitate towards targeted approaches. The statements below indicate that this shift occurred because policy makers were more accustomed to implementing targeted policies and programs. Embedded ways of knowing and doing can restrain innovation when it comes to creating JUG (O'Flynn et al. 2011). Hence, while the 'vision' of the SIA was one of welfare state strengthening, in implementation it increasingly became focused on developing policies and programs targeted towards specific groups in need, as policy makers adapted the new values to existing practices (rather than the reverse):

When it was set up it was very much about the Australian community to be as inclusive as possi- ble, and providing people with the opportunities to connect, everyone to connect with the community in a meaningful way. ... That is obviously a very laudable aim to have, but the question becomes, well what does that mean in practice?... In terms of what a small group of people can do, it has to be focused on the most disadvantaged... you do a little bit of work on everything and then you have no impact. I think in theory it's everyone, but in practice, my observation is if it's not focused, it's kind of just useless ... [G03]

We're looking for every Australian to participate economically, socially, every demographic, in the process and those sorts of things... In amongst all of that, what should the Social Inclusion Agenda focus on? ... So the social inclusion vision is that all-encompassing thing, but the social inclusion... mission is about making a system more accessible for the most vulnerable people [G06]

Here, we can see that policy makers attempted to apply the new values articulated by the policy current of social inclusion to their practice. This shifted the policy narrative from an institutional intervention to a process intervention, producing mixed results. Policy makers were unsure of how to contribute to such a broad and expansive vision, arguing that universal approaches to social policy are ineffective and impossible to implement. They believed that as a policy 'about everyone' (both in the sense that the SIA was concerned with the whole population, and that 'everyone' needed to be included in society), the SIA would become diluted, generating little change or impact. Consequently, policy makers felt justified in their attempts to narrow or 'sharpen' the focus of the Agenda to ensure that it could be successfully implemented. In concentrating on a more targeted approach, they fell back on their existing practices (and what had 'worked' in the past).

The experience of the SIA demonstrates the importance of context for creating JUG. As Giddens (1984) has argued, action is 'historically conditioned'; our actions are deeply coloured by our past experiences and existing knowledge, which we draw on in order to act. The relationship between past experiences and future actions is therefore recursive; social 
systems (such as organizations and institutions) cannot exist without agency, but actors do not create new social systems each time they act. This 'duality of structure' means that agency is deeply embedded in context (Giddens 1984). That is, our actions are shaped - or determined - by our contexts (or 'structure'). However, in return, our actions also reproduce our context. For example, day-to-day practices, such as social courtesies, create the social norms (or authoritative structures) that govern future behaviour. This means that existing ways of knowing and doing are authoritative, making them difficult to change.

The implementation experiences of the SIA also demonstrate that efforts to create JUG can be undermined by a mismatch between communicative and process level instruments and actions. Gallop describes the SIA as a 'complex' agenda that was unlikely to be given the requisite 'free run' within government to be successful (Gallop 2010). Instead, he argued, it would continue to compete with other issues. Hence, although a policy narrative articulates a government's overarching objectives and values, governments and policy makers are subject to a range of pressures at any given time:

Politics drives everything. If an area is not part of their interest or it's slightly less of interest and they've got a different agenda then that's where the resources shift. [G02]

Governments have to take it in the context of everything else, they have to take it in the context of other pressures, of fiscal pressures. [G01]

Policy narratives, it seems, can be disrupted by policies that are adopted in reaction to other pressures, but not necessarily consistent with the overall vision. In the case of the SIA, significant political manoeuvring occurred, which saw different policies become associated with the Agenda for politically expedient purposes:

I think part of that cynicism developed because things were attached to the Social Inclusion Agenda, which really weren't.

Each time the government had to justify what it was doing in terms of social inclusion, it would just roll out a whole lot of social policy initiatives, not really social inclusion issues, because if it was listing social inclusion initiatives, it probably would have been quite an embarrassingly short list. [G03]

Similarly, in the next statement a senior policy maker outlines an example of how a social inclusion lens was retrospectively given to policies to justify policy decisions:

A really good example of the disjuncture was the last budget where the government announced the 10 trial sites and a range of other reforms to try and get people who are most disadvantaged into participating in the economy... but trying to get that to happen across the country... they couldn't afford to do that. So they said 'ok we'll do it in 10 sites'. So then they retrofit a 'placebased' agenda and they locate the evidence for what they're doing through The Social Inclusion Board. The truth is the policy process had nothing to do with the Social Inclusion Board at all, it was a convenient justification of what they did. And policymaking is chaotic like that, it doesn't follow a linear process and it's not all neat. [G05]

The disjuncture that this manoeuvring created between the communicative intervention of social inclusion as a policy narrative and process level change ultimately undermined JUG efforts:

What happens is it undermines the social inclusion, [I] just think that's the bottom line. You can try and talk your way out of it, but actions speak louder than words, so if you're doing that stuff, I think it undermines your credibility in terms of the Agenda. [G03]

Here, the government may have achieved its immediate goal (that is validating a particular course of action), but the overall cost is high - destabilizing efforts to create JUG. The SIA was particularly vulnerable to this problem because of the nebulous nature of 'social inclusion'. Social inclusion has been shown to be a poor concept for policy, open to interpretation, and able to justify highly diverse policy strategies (Levitas 1998). For the SIA, this meant that it could be adapted and applied to a range of policies and strategies that were not necessarily consistent with one another. As Pollit (2003: 47) contends, 'Ministers may not be able to create JUG on their own, but they can certainly undermine it'. 
Potentially, social exclusion could have provided a stronger framework for achieving the goals of the SIA. Social exclusion has been a policy theme in Europe since the 1970s (Silver 1994). The concept more clearly places the responsibility on government to change the structures of society that generate social inequality. This would require a stronger interventionist role for government in society and a shift away from residual, or targeted, approaches. However, as the work of Levitas (1998) has shown, social exclusion is also susceptible to co-option: forming the basis of residual and individually targeted social policy in the United Kingdom.

Communicative interventions, like policy narratives, which are aimed at creating institutional change are seen as 'soft' interventions that lack substance and are not intended to create changes in practice themselves, but rather 'set the scene' by shifting values (de Bruijn and Heuvelhof 1997). The SIA suggests that they can have significant implications for the design of policies and programs. The implementation experiences of policy makers also indicate that inconsistencies between communicative instruments used to create institutional change and action at the process level can devalue efforts to create JUG in the eyes of policy makers.

\section{The Challenges Associated with New Administrative Structures}

The second point of intervention for the implementation of the SIA was the creation of new administrative structures, aimed at creating integration and coordination between different departments in order to achieve more effective policy solutions. The Social Inclusion Unit was principally responsible for driving and coordinating action on social inclusion across government and creating alignment between policies developed in different areas of government. Although the Unit was placed in the Department of PMC to give it greater authority, policy makers felt that this created an odd structure, where the Unit was detached from the Minister for Social Inclusion $^{1}$ :
It becomes awkward, there's ambiguity. And I fully understand why they put that in there because they wanted to make sure that people had some clout, the concept had some clout and it has Prime Ministerial backing... But that split responsibility can be quite tricky to manage. [G02]

I mean it's often a little difficult because the Social Inclusion Unit's in [Prime Minister and Cabinet (PMC)]. In terms of structure, when it was set up Gillard was the Minister of Social Inclusion in [the Department of Education, Employment and Workplace Relations (DEEWR)], but the Social Inclusion Unit was in Prime Minister and Cabinet, [reporting to] the Prime Minister. So that was really silly. I didn't like that because she was the Minister for Social Inclusion and yet she was getting serviced by PMC on that one issue. [G04]

This arrangement was described as limiting the ability of the Social Inclusion Unit to work across government, and with ministers, to drive the implementation of the SIA:

There was an odd political structure where you've got it sitting in PMC and it sort of makes sense but... the Social Inclusion Unit, you know, it's not necessarily a driver. It could be, but [not] if the minister is somewhere else while they're still sitting in the Prime Minister's Department. So they've got two or three masters so they're not quite sure how to work with them... They're sitting in PMC to give it some clout, but their ministerial responsibility belongs to PMC... not the minister [who is] responsible for policy. So the organisational structure [gets] in the way of the relationship. [G02]

Hence, participants found crossdepartmental briefing and responsibility to be problematic. This speaks to the persistent nature of existing - and historically conditioned - actions, which makes substantive shifts in practice difficult to achieve (Giddens 1984). Interestingly, participants conceptualized strong mechanisms as being based within the existing siloed departmental structure, undermining the SIA at its most basic level. In short, for our participants, the way to make JUG most effective is to not join up government at all.

The finding that interdepartmental units are unable to generate collaborative action across departments is consistent with other empirical 
research on JUG (Davies 2009; James 2004; Keast 2011; Klijn and Koppenjan 1997). The Social Inclusion Unit had no formal authority over other departments, limiting its ability to influence activities across government departments. Interdepartmental groups charged with leading JUG that have no formal authority in other departments generate limited change and create 'serious dysfunction' (O'Flynn et al. 2011). As can be seen in the statements by policy makers and their frustration at the placement of the Unit, developing interdepartmental committees can end up creating new teams and administrative structures that are not well integrated with existing departments. Here, departments continue to carry the burden of accountability and implementation, whereas interdepartmental teams generate ideas, but lack the implementation capacity or accountability mechanisms to get things done.

The effectiveness of external advisory committees for facilitating JUG has received little attention. The Social Inclusion Board, which was created to provide advice to government on policy directions, was found to suffer from many of the same limitations as the Social Inclusion Unit. Due to its affiliation with the Social Inclusion Unit, the Board was also placed in PMC. Like the Social Inclusion Unit, the placement of the Board outside the main social policy departments was seen as problematic for exerting influence over policy makers, and creating integration:

I think it's the absence of a very clear mission and the absence of connectiveness to what the government is doing ... I think that the leadership or central driving force with social policy revolves around Jenny Macklin ${ }^{2} \ldots$ she's a really, really strong force in determining where social policy goes. So Prime Minister and Cabinet aren't in the social policymaking processes they might have been previously. And so you've got the Social Inclusion Board sitting over here in PMC and in actual fact if we're honest, if they cared about social inclusion, you'd say the best possible place for that Board to be in FaHCSIA [Department of Families, Housing, Community Services and Indigenous Affairs], under Macklin. [G05]

Participants felt that the Board therefore needed to be better integrated into the public service for this to be shifted beyond a consultative role into a policy-making role:

But some of those people are regular people we consult on a range of things so it's not as if they don't get a hearing. It's a question of how you actually harness that experience and use it and I don't think we've spent a lot of time [on this] and I think the bureaucracy is mixed up there.

We should have grabbed hold of that opportunity and worked with it but now it's one of those boards that will always be there and it will just do what it does and ask for us to do work that they want us to do, but I don't know how much influence it has or where it takes us... It's very hard to deal with those sorts of bodies. They can be very effective but they can be also just what they are, a collection of individuals with different viewpoints. [G02]

Research into JUG indicates that initiatives that seek integration across government, coupled with changes to systems and processes, require a 'supportive architecture' within government (O'Flynn et al. 2011). This is particularly the case for initiatives that seek systemic change, requiring high degrees of collaboration and integration (Keast 2011). Strong accountability and incentive mechanisms can support integration and create formal relationships and structures between interdepartmental committees, advisory bodies, and departments. Without these structural mechanisms, initiatives like the SIA are unlikely to produce significant or sustained change (Bardach 1998). This can be seen in participants' desire to locate the Agenda within a single department (be it 'FaHCSIA' or 'DEEWR'). Shifting these historically conditioned perceptions requires more nuanced interventions, such as new lines of accountability and reporting, changes to financing structures, training, and incentive mechanisms. JUG needs multiple interventions andflexibility, so that mechanisms can be added, removed, or refined as 'joining up' progresses.

In examining the interrelationships between the intervention points for the SIA, this paper demonstrates the importance of establishing coherence between institutional and operational level action in implementing JUG. Although communicative instruments, such as 
policy narratives, are thought to merely 'set the scene' for future change, this research found that policy makers attempted to operationalize the policy narrative by applying it to their practice. In the absence of greater clarity, accountability, and incentive mechanisms between new administrative structures and departments, the narrative of social inclusion carried insufficient weight to change the practice of policy makers. As a result, they adapted 'social inclusion' to their existing ways of knowing and doing, resulting in the SIA 'washing out' and creating little change.

One of the key challenges revealed by the experience of the SIA is how to keep joined-up initiatives alive in the face of politics and government machinations. Under the SIA, some policies became associated with the Agenda, which were not consistent with the narrative of social inclusion. This type of political manoeuvring is a natural part of the governing process and, as a result, unlikely to change (Kingdon 1984). Hence, efforts to create JUG need to be robust enough to withstand flow on effects from the political process. Careful attention needs to be given to what concepts are used as institutional instruments, whereas a stronger supportive architecture is required in order to buffer joined-up initiatives from shocks from the external environment.

O'Flynn et al. (2011) suggest that a strong supportive architecture for JUG would take a 'matrix' form, emphasizing horizontal and vertical integration and support. In a related publication, the authors provide clear guidance on the specific elements of such an architecture based on an evidence review (Carey et al. 2014). This includes strong accountability and incentive mechanisms, dedicated resources, training, and skill development, alongside the elements found in the SIA (such as a mandate for change and a policy narrative).

\section{Conclusion}

Emerging evidence on JUG implementation demonstrates the need for compatibility between goals, the instruments, and processes used to achieve them, their level of deployment, and the context in which change is pursued.
The literature also emphasizes the need for 'fit-for-purpose' strategies (Keast 2011). The experiences of the SIA in this research support these arguments, demonstrating that consistency between instruments, processes, and actions is critical to the success of joined-up initiatives. The research also lends weight to existing research suggesting that interdepartmental groups are limited in their ability to create integration between departments. Moreover, it highlighted that many of the problems identified in the literature with regard to these groups also apply to external advisory committees.

More attention needs to be given to developing a 'supportive architecture' around these groups. Existing research indicates that this should start with developing incentive mechanisms and clear lines of accountability.

\section{Endnotes}

1. The Ministry for Social Inclusion was associated with the Department of Education, Employment and Workplace Relations.

2. Minister Macklin was the Minister for Families, Community Services and Indigenous Affairs.

\section{References}

6, P. 2004. 'Joined-Up Government in the Western World in Comparative Perspective: A Preliminary Literature Review and Exploration'. Journal of Public Administration Research and Theory 14:103-138.

Australian Public Service Commission. 2007. Tackling Wicked Problems: A Public Policy Perspective. Canberra: Australian Public Service Commission.

Bardach, E. 1998. Getting Agencies to Work Together: The Practice and Theory of Managerial Craftsmanship. Washington, DC: Washington University Press.

Bartel, C. A. and R. Garud. 2009. 'The Role of Narratives in Sustaining Organizational Innovation'. Organization Science 20:107-117.

Bills, D. 2001. 'Tackling social exclusion: The contribution of voluntary organisations'. In M. Harris and C. Rochester (eds.), Voluntary Organisations 
and Social Policy in Britain (pp. 37-48). London: Palgrave.

Carey, G., Crammond, B. and Riley, T. 2014. 'Top-Down Approaches to Joined-Up Government: Examining the Unintended Consequences of Weak Implementation.' International Journal of Public Administration 1-12. doi:10.1080/01900692.2014.903276

Christensen, T. and P. Laegreid. 2006. The Whole of Government Approach: Regulation, Performance and Public Sector Reform. Working Paper, 6th ed. Bergen: Stein Rokkan Centre for Social Studies.

Christensen, T. and P. Laegreid. 2007. 'The Whole-of-Government Approach to Public Sector Reform'. Public Administration Review 67:10591066.

Commonwealth Department of Family and Community Services. 2005. Joining Up Services for Homeless Jobseekers. Final Report for the National Homelessness Strategy. Canberra: Australian Commonwealth Government.

Commonwealth of Australia. 2009. The Australian Public Service Social Inclusion Policy Design and Delivery Toolkit. Canberra: Commonwealth Government of Australia.

Davies, J. S. 2009. 'The Limits of Joined-Up Government: Towards a Political Analysis'. Public Administration 87:80-96.

De Bruijn, J. and E. Heuvelhof. 1997. 'Instrument for Network Management'. In W. Kickert, E.-H. Klijn, and J. Koppenjan (eds.), Managing Complex Networks: Strategies for the Public Sector (pp. 166-191). London: Sage.

Friedman, B. 2006. 'Policy analysis as organisational analysis'. In M. Moran, M. Rein, and R. Goodin (eds.), The Oxford Handbook of Public Policy (pp. 496-528). Oxford: Oxford University Press.

Gallop, G. 2010. 'In Defence of Federalism'. In N. Dyrenfurth and T. Soutphommasane (eds.), All That's Left: What Labor Should Stand For (pp. 77-95). Sydney: UNSW Press.

Giddens, A. 1984. The Constitution of Society. Cambridge, UK: Polity.

Gillard, J. and P. Wong. 2007. 'An Australian Social Inclusion Agenda'. Australian Labor Party. Canberra: Australian Labor Party.

Hill, M. and P. Hupe. 2009. Implementing Public Policy, 2nd ed. London: Sage.

Homel, P., B. Nutely, A. Webb and N. Tilley. 2004. Investing to Deliver: Reviewing the Implementation of the UK Crime Reduction Program. London: Home Officer Research, Development and Statistics Directorate.
James, O. 2004. 'The UK Core Executive's Use of Public Service Agreements as a Tool of Governance'. Public Administration 82:397-419.

Keast, R. 2011. 'Joined-Up Governance in Australia: How the Past Can Inform the Future'. International Journal of Public Administration 34:221231.

Kettl, D. 2000. 'Public Administration at the Millennium: The State of the Field'. Journal of Public Administration Research and Theory 10:7-34.

Kingdon, J. 1984. Agendas, Alternatives, and Public Policies. Boston: Little, Brown.

Klijn, E.-H. and J. Koppenjan. 1997. 'Public Management and Network Management: An Overview'. In W. Kickert, E.-H. Klijn, and J. Koppenjan (eds.), Managing Complex Networks: Strategies for the Public Sector (pp. 35-60). London: Sage.

Klijn, E.-H. and J. Koppenjan. 2000. 'Public Management and Policy Networks'. Public Management 2:437-454.

Levitas, R. 1998. The Inclusive Society? Social Exclusion and New Labour. London: MacMillan Press.

Lipsky, M. 1980. Street-Level Bureaucracy. New York: Sage.

Meyers, M. and N. Dillon. 1999. 'Institutional Paradoxes Why Welfare Workers Cannot Reform Welfare'. In G. Frederickson and O. M. Johnston (eds.), Public Management Reform and Innovation: Research, Theory, and Application (pp. 230259). Alabama: The University of Alabama Press.

Miller, H. 2012. Governing Narratives: Symbolic Politics and Policy Change. Tuscaloosa: University of Alabama Press.

O’Flynn, J. 2013. 'Crossing Boundaries: The Fundamental Questions in Public'. In J. O'Flynn and J. Wanna (eds.), Crossing Boundaries in Public Management and Policy: The International Experience (pp. 11-44). London: Routledge.

O'Flynn, J., F. Buick, D. Blackman and J. Halligan. 2011. 'You Win Some, You Lose Some: Experiments with Joined-Up Government'. International Journal of Public Administration 34:244-254.

O'Reily, K. 2005. Ethnographic Methods. Oxon: Routledge.

Office of Women's Policy. 2002. Women's Safety Strategy: A Policy Framework. Victoria: Department of Premier and Cabinet.

Pollitt, C. 2003. 'Joined-Up Government: A Survey'. Political Studies Review 1:34-49.

Pressman, J. and A. Wildavsky. 1984. Implementation. Berkley: University of California Press. 
Riccucci, N. M., M. Meyers, I. Lurie and S. J. Han. 2004. 'The Implementation of Welfare Reform Policy: The Role of Public Managers in FrontLine Practices.' Public Administration Review 64:438-448.

Richards, S. 2001. Four types of joined-up government and the problem of accountability. Annex to National Audit Office Joining Up to Improve Public Services (HC 383 2001-2002). London: TSO.

Rittel, H. W. and M. M. Webber. 1973. 'Dilemmas in a General Theory of Planning'. Policy Sciences 4:155-169.

Ross, S., M. Frere, L. Healey and C. Humphreys. 2011. 'A Whole of Government Strategy for Family Violence Reform: A Whole of Government
Strategy for Family Violence Reform'. Australian Journal of Public Administration 70:131-142.

Sandfort, J. 1999. 'The Structural Impediments of Human Service Collaboration: Examining Welfare Reform at the Front Lines'. Social Service Review 73:314-339.

Silver, H. 1994. 'Social Exclusion and Social Solidarity: Three Paradigms'. Labour Review 133:531-574.

Smircich, L. 1983. 'Studying Organisations as Cultures'. In G. Morgan (ed.), Beyond Method: Strategies for Social Research (pp. 160-172). California: Sage.

Strauss, A. 1987. Qualitative Analysis for Social Scientists. Cambridge: Cambridge University Press. 